\title{
Processes for preparing lithia
}

\section{Fuchs}

To cite this article: Fuchs (1838) Processes for preparing lithia, Philosophical Magazine Series 3, 13:83, 393-393, DOI: $10.1080 / 14786443808649600$

To link to this article: http://dx.doi.org/10.1080/14786443808649600

册 Published online: 01 Jun 2009.

Submit your article to this journal 준

LII Article views: 2

Q View related articles $₫$ 
this acid is present however, the hydrochloric acid becomes rapidly brown, by repose depositing a precipitate of that colour, consisting of an intermediate sulphuret of tin, of proto-sulphuret and of chloride of tin insoluble in muriatic acid. This reaction depends upon a portion of the tin becoming oxidated at the expense of the sulphurous acid, another portion uniting with the sulphur, while the oxide of tin thus formed dissolves in the excess of muriatic acid to form an insoluble chloride.-Journ. für Pract. Chemie, 6. 81 .

PROCESSES FOR PREPARING LITHIA. BY FUCHS.

1. Lepidolite is to be ignited during two hours with $I \frac{1}{2}$ or 2 parts of quicklime, and the mass left during two or three months exposed to the air, it being kept constantly moist with water. The whole is then to be powdered and treated with water, which dissolves out potassa and lithia; the solution is then saturated by a current of carbonic acid gas and evaporated to dryness. The residue, which consists of the carbonates of potassa and lithia, is digested with water containing a little alcohol, which dissolves the carbonate of potassa and leaves the carbonate of lithia.

2. Seven parts of lepidolite are ignited with 2 of calcined vitriol, taking care that the mixture never melts. The mass when cold is powdered and boiled with water, which dissolves out the sulphates of lithia and potassa : the solution is then evaporated to dryness, and the silt of lithia dissolved out by water, to which a little alcohol has been previously added.-Jahres-Bericht der Phys. Wissenschaften 16. 97 .

\section{NEW DOUBLE SALT OF ZINC AND POTASSIUM. BY AN'LHON.}

When a solution of iodide of potassium is mixed with one of nitrate of zinc, a yellowish crystalline deposit of iodide of zinc falls, which dissolves on the addition of an excess of iodide of potassium, and by evaporation crystallizes in colourless octohedral or rhombic crystals, which are not altered by exposure to the air, and contain iodine, nitric acid, zinc, and potassa. By exposure to heat this salt evolves iodine, then nitrous acid, oxide of zinc and potassa being left; it is readily soluble in water, insoluble in alcohol; acids precipitate iodine from its solutions, tartaric acid separating bitartrate of potassa. -Buchner's Reperiorium, 1. 115.

\section{REAGENT FOR NITRIC ACID AND NITROGEN. BY DESBASSAYNS DE RICHEMONT.}

The mode of detecting the presence of nitric acid proposed by De Richemont is exceedingly delicate, and depends upon the fact, that a mixture of a concentrated solution of protosulphate of iron and sulphuric acid becomes coloured rose-red by the addition of deutoxide of nitrogen (Sickoxyd), or even purple if the latter is present in larger proportion: the quantity of the nitric oxide necessary for the production of this tint is so small that an exceedingly minute portion may be detected by it. To detect the presence of nitric acid, add to a small quantity of sulphuric acid the solution to be examined, in 